\title{
Effect of Morinda Citrifolia Linn on Lung Cancer Promotion: Experimental Study
}

\author{
Gabriela de Marco Cuginotti, Caroline Garcia Francisco, Maria Fernanda Ribeiro Cury, Luiz \\ Gabriel Milanez Ronchi, Luiz Sergio Milanez Ronchi, Rafael de Oliveira Guena, Thalyta \\ Aparecida Leite de Lima, Ana Laura Carvalho Achkar, Ricardo Ajeje Lobo, Pedro Henrique \\ Gayer Vilela, Patrícia Maluf Cury, Tamara Veiga Faria*. \\ Faceres medice school - Avenida Anísio Haddad number 6751, São José do Rio Preto, São Paulo, Brazil.
}

${ }^{*}$ Corresponding Author: Tamara Veiga Faria, Faceres medice school - Avenida Anísio Haddad number 6751, São José do Rio Preto, São Paulo, Brazil.

\begin{abstract}
The Morinda citrifolia linn, is an example of a medicinal plant widely used by the population. Our study aims to investigate the therapeutic effect of Noni on the experimental lung cancer. To this purpose, 40 male Balb/c mice were divided into two groups: 20 animals in the control group and 20 in the Noni group, all of which were induced to lung carcinogenesis with intraperitoneal urethane. For the experiment, the animals were offered $250 \mathrm{ml}$ of $50 \%$ Noni juice until the treatment was completed after 90 days. The animals of the control group were responsible for the largest number of histological alterations. It was observed that $68 \%$ of the animals in the control group presented some histological alteration classified in: 9 (69,2\%) of the animals presented pneumonia, $1(14,28 \%)$ presented pulmonary nodule, while in the Noni group, the prevalence of pulmonary nodules represented $100 \%$ of the animals with histological changes. When comparing the study groups, statistical differences were identified in the variables "pneumonia" and "presence of pulmonary nodule", representing $p=0.030$ and $p=0.048$, respectively. The concentrated juice of Morinda citrifolia linn can act as a lung cancer promoter, emphasizing its function in cell proliferation, antibiotic and antiinflammatory action.
\end{abstract}

Keywords: Preclinical study, MORINDA CITRIFOLIA LINN, Noni, lung cancer, Promotion cancer.

Abbreviations: Noni: Morinda Citrifolia Linn

Control group: group of animals treated for 90 days with water.

Noni group: group of animals treated for 90 days with Noni.

\section{INTRODUCTION}

Smoking considered a carcinogenic agent, environmental pollution, allergens, occupational agents, genetic, social and lifestyle factors are important risk factors for chronic respiratory disease, including lung cancer that is becoming increasingly prevalent in the world population and represents a challenge for traditional medicine. About $7 \%$ of global mortality, that is, approximately 4.2 million deaths are caused by chronic respiratory disease ${ }^{[1,2]}$.

In this context and considering the search for treatment of lung diseases, Brazilian biodiversity associated with ethical and cultural diversity add natural plants as a therapeutic option ${ }^{[1]}$. Medicinal plants are considered to be a readily available medicine in nature, with properties to relieve diseases symptoms and even cure pathologies ${ }^{[3]}$. These natural medicinal products have been used for thousands of years and remain important for the innovation and discovery of new drugs ${ }^{[4]}$. It is estimated that approximately US\$ 60 billion per year are destined to the medicinal plants market ${ }^{[5]}$, which have great potential in the development of research with technological and therapeutic results, including dosage and potential adverse events ${ }^{[1]}$.

Morinda citrifolia linn, popularly known as Noni, is an example of a medicinal plant widely used by the population. It is a plant originating from Southeast Asia and was introduced in different Brazilian regions as a food source and, mainly, as a raw material for herbal medicines, due to all the beneficial health characteristics attributed to it ${ }^{[6,7]}$. 
It can be considered a traditional plant because its medicinal value has been known for over 2000 years. It represents an indigenous medicinal plant that is popularly used for disease prevention and treatment of chronic diseases such as lung cancer ${ }^{[5]}$.

Although there are few preclinical and clinical studies, some possible benefits have been identified, among which are: antibacterial, antiviral, antifungal, antitumor, anthelmintic, antioxidant, analgesic, anti-inflammatory and hypotensive activity, besides its role in the regulation of cellular functions and serum cholesterol levels ${ }^{[6,7,8]}$.

In this context and considering the need for preclinical studies of Noni and definition of its real benefits, the present study aimed to analyze the effect of Morinda citrifolia linn on the experimental lung cancer.

\section{Materials ANd Methods}

\subsection{Animals}

All experimental procedures were conducted according to the guidelines for biomedical research stated by the Brazilian Societies of Experimental Biology and approved by the Ethics Committee on Animal Experimentation of FACERES School of Medicine with protocol number 013/2017. Forty male Balb/c mice were used and divided into two groups: control group (group C) with 20 animals and noni group (group N) with 20 animals randomly allocated. All animals received the carcinogen at seven to nine weeks of life and were in the same dietary and environmental conditions. They were placed in individual cages at $22^{\circ} \mathrm{C}+/-2^{\circ} \mathrm{C}, 60 \%$ relative air humidity and submitted to 12 hours of light and 12 hours of darkness per day.

The lung cancer was induced with urethane, an ethyl ester of carbamic acid that induces tumor formation intraperitoneally at a dose of $3 \mathrm{mg} / \mathrm{kg}$ from a $10 \mathrm{ml}$ base solution of $0.9 \% \mathrm{NaCl}$, fractionated in two equal doses of $1.5 \mathrm{mg} / \mathrm{kg}$, with 48 -hour intervals between them ${ }^{[9]}$.

After being induced to carcinogenesis, the mice were observed for 16 weeks (time needed for development of the pulmonary nodules), always being fed with free food, water and having their cages sanitized ${ }^{[9]}$. They were also weighed and closely monitored to record any changes and complications.

\subsection{Preparation of Morinda Citrifolia Linn Concentrated Juice}

The fruits of Morinda citrifolia linn were acquired in São José do Rio Preto (SP) and selected according to the degree of ripeness. Thus, the whitish yellow fruits were used ${ }^{[7]}$. The pulp was obtained by centrifuging the whole fruits, without any vehicle and without sugar or sweetener, until a homogeneous mixture was obtained; then the pulp was weighed, and, from weight, water was added to achieve the $50 \%$ concentration. For the experiment, the animals were offered $250 \mathrm{ml}$ of $50 \%$ Noni juice for 48 hours until 90 days of treatment were completed. If the mixture was not ingested during this period, it was discarded. To control the amount ingested, the volume of liquid on the troughs was measured. This procedure was similarly done in the control group, where water was used.

The animals were sacrificed with anesthetic overdose, being $20 \mathrm{mg} / \mathrm{kg}$ of Xylazine Hydrochloride and $170 \mathrm{mg} / \mathrm{kg}$ of Ketamine. During necropsy, a macroscopic analysis of all abdominal organs was performed, and the lungs, liver, kidney and brain were dissected. The lungs were submitted to macroscopic analysis by counting the pulmonary nodules seen by magnifying glass after tracheal pulmonary insufflation ${ }^{[9]}$. The other resected organs were also macroscopically evaluated to identify possible metastases, as well as to verify the presence of possible compromised lymph nodes.

For microscopic analysis, slides with representative cuts of the resected organs (lungs, liver and brain) were made using Hematoxylin-Eosin staining in 5mm thick sections.

In the analysis of liver and kidney sections, necrosis, vascular congestion and inflammatory processes were observed, as well as changes and glomerular sclerosis in the renal sections and the presence of hepatic steatosis in the evaluation of liver tissue.

\subsection{Statistical Analysis}

Statistical analyzes were performed using the nonparametric Kruskal-Wallis and Mann-Whitney tests with the SPSS version 24.0 software. The histological evaluation variables were analyzed by the Mann Whitney test. The significance level established will be less than or equal to 5\%.

\section{RESULTS AND DISCUSSION}

In the present study, we chose to use the experimental model of lung cancer to identify how the investigational product acts on tumor development and observe different data from the current literature. 
It is valid to consider that the juice produced from Morinda citrifolia linn is made with the ripe fruit and its use is frequent in the population, including for the treatment of chronic diseases ${ }^{[10]}$. Our study chose to reproduce what is most common in our population, that is, the data illustrate that patients on

lung cancer treatment who use Noni fruit juice may have negative interference in their therapeutic response.

Thirty-nine animals were used for the study, one of them in the control group died during the tumor induction period and before starting the drug study. The data obtained in the histological analysis by comparing the control group and the Noni group showed that $68 \%$ of the animals in the control group were responsible for the largest number of histological changes, including any histological images other than normal.

Statistical analysis showed a difference between groups with $\mathrm{p}=0.020$, representing a greater pulmonary impairment in the control group. However, considering the classifications of the histological alterations found, the animals of the Noni group presented higher number of neoplastic lesions, as described in table 1 .

Table 1 - Histological changes classified as pneumonia, presence of pulmonary nodule, Xanthomatous macrophages and hyperplasia.

\begin{tabular}{|c|c|c|c|c|c|c|c|c|c|c|}
\hline & \multicolumn{10}{|c|}{ Pulmonary histological changes } \\
\hline & \multicolumn{2}{|c|}{$\begin{array}{c}\text { No } \\
\text { change }\end{array}$} & \multicolumn{2}{|c|}{ Pneumonia } & \multicolumn{2}{|c|}{ Nodule } & \multicolumn{2}{|c|}{$\begin{array}{l}\text { Presence of } \\
\text { Xanthomatous } \\
\text { macrophages }\end{array}$} & \multicolumn{2}{|c|}{ Hyperplasia } \\
\hline & $\mathrm{N}$ & $\%$ & $\mathbf{N}$ & $\%$ & $\mathrm{~N}$ & $\%$ & $\mathrm{~N}$ & $\%$ & $\mathbf{N}$ & $\%$ \\
\hline $\begin{array}{l}\text { Control } \\
\text { group }\end{array}$ & 6 & 32 & 9 & 69,2 & 1 & 14,2 & $\mathbf{0}$ & $\mathbf{O}$ & 4 & 30,1 \\
\hline $\begin{array}{l}(\mathrm{N}=19) \\
\text { Noni group } \\
(\mathrm{N}=20)\end{array}$ & 13 & 65 & 1 & 14,2 & 7 & 100 & 2 & 28,6 & o & $\mathbf{0}$ \\
\hline
\end{tabular}

It was observed that $68.42 \%$ of the animals of the control group presented some histological alteration classified in: $9(69.2 \%)$ of the animals presented pneumonia, $1(14.28 \%)$ pulmonary nodule and 4 (30.1\%) presented hyperplasia, while in the Noni group the prevalence of pulmonary nodules represented $100 \%$ of the animals with histological alteration. In the Noni group, besides the neoplastic lesions, it was also possible to identify that $2(28.6 \%)$ showed the presence of xanthomatous macrophages, $1(14.2 \%)$ pneumonia in the histological analysis. When comparing the study groups, it was found that the presence of pulmonary nodules was higher in the Noni group $(\mathrm{p}=0.030)$.

Regarding the number of nodules, a total of 12 (twelve) nodules were observed in the Noni group, with an average of approximately 1.7 nodules per animal (total of 7 animals). In the control group, only one nodule was present (Table 1).

Therefore, Morinda citrifolia linn may have shown a promoting action in urethane-induced lung cancer, which could be explained by the fact that this pathology develops in two stages: initiation and promotion. Initiation, defined as permanent damage to the cell's genetic material, is followed by the action of a promoter that does not cause cancer directly, but its collaboration is necessary to allow the cell to remain in the carcinogenic process ${ }^{[1]}$. Our results illustrate the possible promoter activity of Morinda citrifolia linn in lung cancer.

In vitro study showed that the presence of damnacanthal compound attributes to Morinda citrifolia linn the tyrosine kinase inhibitory action, in addition to the possible antiangiogenic potential, suggesting preclinical studies to analyze its real therapeutic potential ${ }^{[11]}$. However, in the present study, we evidenced that, considering the experimental model, the investigational product, at the dose used, can activate the tyrosine kinase process resulting in the promotion of the neoplasia.

Unlike our study, which used Morinda citrifolia linn pulp, an in vitro and in vivo study with its leaves, traditionally consumed as vegetables in the treatment of metastatic lung cancer showed that Noni leaves are capable of inhibiting cell proliferation on lung cancer in small cells and may be able to induce cell cycle arrest in the G0/G1 phase. It also increased Tp53 gene expression, which is likely evidence of anti-apoptotic activity ${ }^{[12]}$. 
Erlotinib Hydrochloride is currently an effective therapy for lung cancer with epidermal growth factor receptor mutation (EGFR) ${ }^{[12,9]}$. In this study by LIM and colleagues, in an animal model, a comparison was made between the therapeutic response of Erlotinib and Noni leaf extract, which evidenced the probable potential of the natural product leaf in tumor suppression when compared with commercial therapy for its action in enhancing the immune response, suppressing proliferation and interfering with various signaling pathways for tumor development ${ }^{[12]}$.

Unlike other studies already published, our study used Morinda citrifolia linn concentrated juice at 50\% for 90 days, which represents the highest dosage established by the scientific literature ${ }^{[7]}$ and this may have contributed to the promotion of neoplastic disease.

Another relevant result of the present study was the majority of cases of pneumonia in the control group being, when compared to the Noni group, statistically significant $(\mathrm{p}=0.48)$. All animals were in the same environment, therefore exposed to the same conditions, but in separate boxes for animals of the Noni group and control, thus, the spread of the disease in the groups may have occurred. We had only one noni group animal, this finding allowed us to highlight the antibiotic and anti-inflammatory activity of the fruit in the other animals of this group. According to NWORU and colleagues, this fruit has antiinflammatory properties, which may clarify some of the beneficial effects of the plant in the treatment of infections and immune inflammatory disorders ${ }^{[13]}$.

Another possibility for the cause of pneumonia in experimental animals considering the experimental model adopted could be the gavage procedure ${ }^{[8]}$ (FARIA, 2017), however, we did not perform this procedure in our study.

According to LIM S. L. et al. (2016), Noni leaf extract may inhibit inflammatory markers of cyclooxygenase $2(\mathrm{COX} 2)^{[12]}$. This activity could be present in the fruit, which could contribute to the improvement of pneumonia.

It is already described in the scientific literature that Noni has antimicrobial activities. Presents substances such as iridoids, methanol, ethyl acetate and hexanes, which are substances with potent antimicrobial potential against the agents Bacillus subtilis, Staphylococcus aureus, Lactococcus lactis, Streptococcus thermophilus, Pseudomonas aeruginosa, Salmonella typhi, Escherichia coli, Vibrio harveyi, Klebsiella pneumonia, Shigella flexneri, Salmonella paratyphi A, Aeromonas hydrophila, Vibrio cholera, Chromobacterium violaceum, and Enterococcus faecalis. There is even antimicrobial evidence against Mycobacterium turbeculosis due to the presence of phenols in its composition ${ }^{[8,14]}$.

Hyperplasia occurs in cells capable of mitosis when stimulated for greater activity and may regress once the causative stimulus has ceased or if the stimulus continues to give rise to other conditions of cellular adaptation and/or transformation such as dysplasia, metaplasia or neoplasia ${ }^{[9]}$.

In the present study, hyperplasia was induced by urethane and identified only in the animals of the control group (Table 1), ( $\mathrm{p}=0.176)$. Although not statistically significant, hyperplasias only identified in the animals of the control group can be considered another finding that contributes to the characterization of Noni as a promoter of the neoplastic process, since this condition may precede the formation of neoplasms.

Similarly, the presence of macrophages was identified only in the Noni group $(\mathrm{p}=0.226)$. The presence of macrophages suggests aspiration bronchopneumonia; however, in the present study, we had no gavage procedures that could explain such finding, thus becoming an occasional finding.

As much as our data represented a worsening in the lungs of the animals regarding the presence of neoplastic lesions, it is worth considering that, in addition to the lung cancer promoting function mentioned previously, Morinda citrifolia linn showed its antiinflammatory and antibiotic activity which was not seen in the control group due to the significant presence of pneumonia.

Therefore, before using Morinda citrifolia linn as a medicinal plant, one should be aware of its effects on the tumor and also evaluate the cost-benefit ratio so that the treatment is performed in a way that offers the best results for the patient, such as the minimum adverse effects and the minimum decrease in the effectiveness of other medicines; however, the current scientific literature cannot define its use safely. Therefore, the importance of the current study is highlighted, which presents additional and conflicting data regarding the studies presented so far. We highlight the potential use of Morinda citrifolia linn fruit, which in cases where there is concomitant exposure with an inducing agent, in high dosage and for a long time, may favor cell proliferation and consequently neoplastic lesions. In addition, induction of urethane as a carcinogenic agent may be equivalent to the potential for smoking in patients who use Morinda citrifolia linn concentrated juice and contribute to lung cancer. 


\section{CONCLUSION}

The fruit of Morinda citrifolia linn concentrate is a medicinal plant used by the world population that in 50\% concentration can act as a lung cancer promoter in the presence of a carcinogenesis inducing agent. At this dosage, its function is related to cell proliferation and favors antibiotic and antiinflammatory action.

\section{REFERENCES}

[1] Ministério da Saúde. Política e Programa nacional de Plantas Medicinais e Fitoterápicos, 1o edição, 1-192, (2016). Brazil.

[2] Araujo L.H, Baldotto C., Jr G.C., et al. Cancer de pulmão no Brasil, J Bras Pneumol. 44(1):55-64 (2018)

[3] Santana S.R. and Neto G.G., Plantas Medicinais Usadas Na Medicina Tradicional Em Dom Aquino, Mato Grosso, Brasil, Flovet, V.1, N.9 (2017)

[4] Santos A.F., Pavão J.M.S.J., Rocha T.J.M., Análise de produção cientifica sobre plantas com potencial antioxidante, antimicrobiano e alopático, DIVERSITAS JOURNAL. V 3, n. 2, 20 (3): 193-200 (2018).

[5] Krishnaiah, D., Bono, A., Sarbatly, R. and Anisuzzaman, S., Antioxidant activity and total phenolic content of an isolated Morinda citrifolia L. methanolic extract from Poly-ethersulphone (PES) membrane separator. Journal of King Saud University - Engineering Sciences, pp.63-67. (2015).

[6] Assis R. M. A, Lameira O. A. and Medeiros A. P. R., Aspectos Fenológicos Do Noni- Morinda Citrifolia Linn. (Rubiaceae), 19o Seminário de Iniciação Científica e 3o Seminário de Pós-graduação da Embrapa Amazônia Oriental (2015).

[7] Achkar A.L.C, Garcia C.F., Cuginotti G., Cury M.F. R., Ronchi L. G. M., Ronchi L. S. M., Guena R. O., Lima T. L., Carlos C. P., Fucuta P.C., Cury, P. M. and Faria, T. V., Preclinical Study of Morinda Citrifolia Linn Concentration and Usage Time and its Liver and Renal Toxicity. International Journal of Medicinal Plants and Natural Products, pp.1-6. (2019).

[8] Assi RA, Darwis Y, Abdulbaqi IM, Vuanghao L, Laghari MJAJoC. Morinda citrifolia (Noni): A comprehensive review on its industrial uses, pharmacological activities, and clinical trials;10(5):691-707. (2017).

[9] Faria T V, Barbosa, S N. Lucio, F Ometto, Lima J P S N, Serrano S V , Cury P M. Blockade of Epidermal Growth Factor Receptor, Cycloxygenase-2 (COX-2) and Mammalian Target of Rapamycin (m-TOR) in Animal Model of Lung Cancer. International Journal of Pharmaceutical Sciences and Drug Research; 8(6):

[10] 281-286. (2016).

[11] Alfano, A. C. A., Padrão Do Uso De Terapias Alternativas/Complementares Por Pacientes Com Câncer De Mama Metastático Em Quimioterapia E Sua Influência Na Qualidade De Vida. Biblioteca da Fundação Pio XII - Hospital de Câncer de Barretos. (2013)

[12] García-Vilas J.A., Pino A. A., Martinez P. B., Quessada A. R., Medina M. A., The noni anthraquinone damnacanthal is a multi-kinase inhibitor with potent anti- angiogenic effects, Cancer Letters. 28; 385: 1-11. (2016).

[13] Swee-Ling Lim, Noordin M. M., Yong-Meng G., Nurul Ain Abu Bakar, Suhaila Mohamed. Metastasized lung cancer suppression by Morinda citrifolia (Noni) leaf compared to Erlotinib via anti-inflammatory, endogenous antioxidant responses and apoptotic gene activation. Mol Cell Biochem. 416(1-2):85-97. (2016).

[14] Nworu CS, Akah PA, Okoye FB, Onwuakagba CJ, Okorafor UO, Esimone CO.Immunological Investigations. Supplementation with aqueous leaf extract of Morinda lucida enhances immunorestoration and upregulates the expression of cytokines and immunostimulatory markers. pp.799-819. (2019)

[15] Candida T., França J.P., Chaves A.L.F., et al. Evaluation of antitumoral and antimicrobial activity of Morinda citrifolia L. grown in Southeast Brazil, 10 - Acta Cirúrgica Brasileira - Vol. 29 (supl. 2) 2014

Citation: Tamara Veiga Faria, et.al., (2019). Effect of Morinda Citrifolia Linn on Lung Cancer Promotion: Experimental Study. International Journal of Medicinal Plants and Natural Products (IJMPNP), 5(4), pp.711. http://dx.doi.org/10.20431/2454-7999.0504002

Copyright: () 2019Authors, this is an open-access article distributed under the terms of the Creative Commons Attribution License, which permits unrestricted use, distribution, and reproduction in any medium, provided the original author and source are credited. 